\title{
Further Training, Educational Needs and Work Challenges of Mental Health Nurses in Greece before the Completion of the Psychiatric Reform
}

\author{
Evmorfia Koukia ${ }^{1 *}$ and John D Papatriantafyllou ${ }^{2}$ \\ ${ }^{1}$ Department of Psychiatric/Mental Health Nursing, National and Kapodistrian University of Athens, Greece \\ ${ }^{2}$ Department of Neurology, Attikon Hospital, Athens, Greece
}

Received: 26 Aug, 2018 | Accepted: 17 Oct, 2018 | Published: 26 Oct, 2018

*Corresponding author: Evmorfia Koukia, Associate Professor in Psychiatric/Mental Health Nursing, RN, CS, Faculty of Nursing, School of Health Sciences, National and Kapodistrian University of Athens, Greece, E-mail: ekoukia@nurs.uoa.gr

Citation: Koukia E, Papatriantafyllou JD (2018) Further Training, Educational Needs and Work Challenges of Mental Health Nurses in Greece before the Completion of the Psychiatric Reform. J Psychiatry Ment Health 4(1): dx.doi.org/10.16966/2474-7769.128

Copyright: (c) 2018 Koukia E, et al. This is an open-access article distributed under the terms of the Creative Commons Attribution License, which permits unrestricted use, distribution, and reproduction in any medium, provided the original author and source are credited.

\begin{abstract}
According to mental health care reform in Greece, psychiatric hospitals had to be closed down for their greater part and units would have been integrated into general hospitals, during the year 2014-2015. The psychiatric care reform is not yet completed. Due to the economic recession of the country, the last 5 years, the Greek government has asked from the European committee an indefinite extension and financial support for the implementation of the psychiatric care reform program. When the reform will take place, psychiatric nurses will be a part of a larger team of nursing staff working in psychiatric outpatients units. The aim of the study was to identify the nurses' educational needs for further training concerning the outpatient provision of care. A questionnaire-based study was conducted among 164 psychiatric nurses working in two major psychiatric hospitals to be closed following the reform. A descriptive analysis was applied to describe nurses' educational needs for further training concerning the outpatient provision of care. The majority of nurses noted that the most important issue in everyday work was effective communication with the client and patient's symptoms management. The nurses thought they lacked management abilities to effectively deliver evidence-based care in community settings. Problems between the health care team (disagreements, miscommunication and violent episodes) and lack of time and personnel were the causes of additional stress in their work. The results have shown that nurses were adequately prepared for clinical care but there is a need for further training especially in law issues and the nursing role in the community settings.
\end{abstract}

\section{Introduction}

Since 1983, Greece has had a number of 10-year National plans for mental health services, co-funded by the EU. The last National plan originated in 1998 was called 'Psychargos' and was divided into three phases: Phase A: 1998-2001; Phase B: 2002-2006 and Phase C: 20062015. The main objectives of this programme were:

i. The deinstitutionalization of the remaining 3000 long-stay patients,

ii. The development of 616 mental health services including community-based structures, rehabilitation units and

iii. The closure of the remaining mental hospitals. (5/9 psychiatric hospitals by the end of 2006 and the remaining by the end of 2015).

According to mental health care reform in Greece, psychiatric hospitals had to be closed down for their greater part and units would have been integrated into general hospitals, during the year 2014-2015. The psychiatric care reform is not yet completed. Only phase A and $\mathrm{B}$ are completed. Due to the economic deprivation of the last 5 years, the Greek government has asked from the European committee for an indefinite extension and financial support for the implementation of the psychiatric care reform program. Phase $\mathrm{C}$ of the Psychargos plan expanded to cover the period 2011-2020. This phase has three lines of action. The first refers to developing regional structures in the community to cover all the needs of the Mental Health and formed on a regional basis. The second refers to designing and implementing strategies to promote the mental health of the general population and the prevention of mental illness. The third relates to organizing the psychiatric care system (sectorization, monitoring, and evaluation) and staff research and training. When the reform process is complete psychiatric nurses will be a part of a larger team of nursing staff working in psychiatric outpatients units [1].

In most countries, the tendency for patients with mental disorders is to receive primary care. The reorganization of the majority of mental health services globally refers to the downsizing of the existing mental institutions, reducing the number of long-stay beds and establishing community services [2]. In order for this care to be more effective, researchers evaluated Nurses' knowledge, skills and designed a training course to meet their needs [3]. Countries like Australia completed the reform years ago and highlighted the pivotal role of the Community Mental Health Nurse (CMHN). A study regarding 
documenting the role of nurse identified six main areas. Day-to-day management of clients, working with clients, working with carers and their families, crisis work for both existing and first-time contacts, and liaison and advocacy work were the areas of the CMHNs' role expansion [4].

In Greece, mental health professionals have in general positive views of the movement of psychiatric care reform, from psychiatric hospitals to extramural services. However, there is no previous study to provide information on the views and needs of nurses working in psychiatric hospitals and how adequately nurses feel they can respond to their role expansion.

\section{Aim of the Study}

The aim of this study was to:

Identify nurses' educational needs for further training concerning outpatient provision of care when working with mental health clients.

Objectives of the present study were to:

- Evaluate nurses' practices in the daily routines

- Identify nurses' coping strategies against stress and workload

- Identify nurses' needs for further training

\section{Subjects and Methods}

\section{Research design}

The study was a wider implementation of a Leonardo Pilot Project (Lifelong Learning Programme) that was carried out in 2009 by Epikouros-DIAN. Training and management Activities in collaboration with other countries. A descriptive research design was used in the study. The goal was to identify nurses' training needs and develop new curriculums for training concerning outpatient psychiatric care in the face of the psychiatric reform.

\section{Setting}

The present study was carried out in the two major psychiatric hospitals in the Athens Metropolitan area, which are to be closed. These two hospitals have inpatient units and extramural facilities as well. These two major psychiatric hospitals have a capacity of 500 and 400 beds respectively. The two large psychiatric hospitals employ both registered nurses (RNs) with a 4-year education and nurses assistants (NAs) with a 2-year education in nursing. A total of 746 nurses are working currently in the two hospitals (260 registered nurses and 486 nurse's assistants).

\section{Subjects}

Questionnaires send to all nurses from the personnel list. The response rate represents $63 \%$ of the total registered nurses $(n=164)$. The sample of the study consisted of 164 full-time registered nurses (4-year education) who worked 37.5 hours per week-three rotating-in inpatient wards in the two major psychiatric hospitals.

\section{Ethical consideration}

Ethical approval for the survey was obtained from hospitals ethics committees. Head nurses of each department were personally contacted by the research team about the aim of the study. Assurances were given concerning confidentiality and anonymity.

\section{Statistical analysis}

Data were collected using the WAP/Vocational training community based Psychiatric nursing questionnaire. This is a self-administered questionnaire with 5 point Likert-like scales and consists of three parts:

I. Questions around daily work

II. Questions along coping with stress and workload

III. Questions concerning the need for further training

An ad-hoc questionnaire was formed to record participants' sociodemographic and professional characteristics. We analyzed results through descriptive analyses.

\section{Results}

The sociodemographic characteristics of the sample are reported in table 1. The final sample consisted of 164 registered nurses. Seventy one (43.2\%) were males and 93 (56.7\%) were females, with a mean age of 30.3 years ( $\mathrm{SD}=5.2$ years; range $21-52$ years). The mean years of work in a psychiatric setting were $5.2(\mathrm{SD}=5.2$ years; range 1-23 years).

\section{Questions concerning daily work}

The majority of nurses considered as "very important" building a relationship with the client (96.9\%), communicating with the client (96.9\%), planning and documenting care (59.7\%), working with doctors (61.6\%) and supporting the client during the personal crisis (84.8\%). They also saw as "very important" stabilizing clients (64.6\%) and supporting the client to manage their health needs (60.3\%).

A significant number of nurses recorded they felt poorly qualified in planning and documenting care (68.3\%), administrative duties (57.9\%), supporting the clients in recognizing their potentials and strengths $(40.8 \%)$ and supporting the clients in self-determination to all decisions concerning their own life (39.0\%) (Table 2).

\section{Coping with stress and workload}

Nurses found extremely difficult (6) or very difficult (5). Having the responsibility for clients in a crisis (39.0\%), "switching-off after work (46.3\%), managing aggression (100\%), managing suicidal behavior (164\%), not having enough time when working with clients $(81.1 \%)$, having problems with the team $(35.3 \%)$ and having problems with "superiors" 76.8\%) (Table 3).

\section{Questions concerning the need for further training}

The topics that nurses wished to cover in a training program were assessment (47.5\%), methodology and models (100\%), the legal background $(92.0 \%)$, professional role in mental health nursing (100\%), reflective practice $(62.2 \%)$, managing crisis (100\%) (Table 4$)$.

Table 1: Socio demographic characteristics of the sample $(n=164)$.

\begin{tabular}{|l|c|}
\hline \multicolumn{1}{|c|}{ Sex } & N\% \\
\hline Males & $71(43.2 \%)$ \\
\hline Females & $93(56.7 \%)$ \\
\hline Age & $\mathrm{x}=30.3 \pm 5.2$ \\
\hline Years of work & $\mathrm{x}=5.2 \pm 5.2$ \\
\hline \multicolumn{1}{|c|}{ Position } & \\
\hline Registered nurse: & $4(2.4 \%)$ \\
\hline 4-yr preparation (university degree) MSc - PhD & $4(2.4 \%)$ \\
\hline $\begin{array}{l}\text { 3-yr preparation-psychiatric nursing } \\
\text { specialty(technological college) }\end{array}$ & $156(95.1 \%)$ \\
\hline 3-yr preparation (technological college) & \\
\hline
\end{tabular}


Table 2: Questions concerning our daily work ( $n=164)$.

\begin{tabular}{|c|c|c|c|c|c|c|c|c|c|c|c|c|}
\hline \multirow{4}{*}{ Areas of activity } & \multicolumn{6}{|c|}{$\begin{array}{l}\text { How important are the following aspects in } \\
\text { your daily work? }\end{array}$} & \multicolumn{6}{|c|}{ How good are you qualified for these areas? } \\
\hline & \multicolumn{6}{|c|}{ On a scale of $6-1$} & \multicolumn{6}{|c|}{ On a scale of $6-1$} \\
\hline & \multicolumn{6}{|c|}{ Very important-unimportant (\%) } & \multicolumn{6}{|c|}{ Very good-poor (\%) } \\
\hline & 6 & 5 & 4 & 3 & 2 & 1 & 6 & 5 & 4 & 3 & 2 & 1 \\
\hline Building a relationship with your client & 97 & 3 & - & - & - & - & 15 & 10 & 22 & 25 & 11 & 16 \\
\hline $\begin{array}{l}\text { Managing and reflecting distance and } \\
\text { proximity }\end{array}$ & 23 & 27 & 22 & 16 & 11 & - & 24 & 6 & 10 & 21 & 26 & 34 \\
\hline Motivating basic self-care & 32 & 22 & 26 & 21 & - & - & 52 & 39 & 4.1 & - & - & 3 \\
\hline $\begin{array}{l}\text { Supporting / advising clients in organising } \\
\text { their daily life }\end{array}$ & 48 & 27 & 12 & 13 & - & - & 17 & 22 & 33 & 12 & 4.8 & 11 \\
\hline Communication with clients & 97 & 3 & - & - & - & - & 17 & 15 & 11 & 15 & 20 & 22 \\
\hline Monitoring Clients & 41 & 59 & - & - & - & - & 13 & 41 & 34 & 11 & - & - \\
\hline Planning and documenting care & 60 & 40 & - & - & - & - & - & - & - & 12 & 20 & 68 \\
\hline Nursing assessment & 16 & 41 & 21 & 21 & - & - & 16 & 14 & 16 & 18 & 20 & 16 \\
\hline Implementing prescribed medical care & 15 & 16 & 16 & 23 & 18 & 17 & 100 & - & - & - & - & - \\
\hline Working with doctors & 62 & 27 & 11 & - & - & - & 22 & 15 & 17 & 10 & 16 & 20 \\
\hline Working with therapists and social workers & 9.1 & 16 & 7.9 & 17 & 27 & 28 & 35 & 15 & 7.9 & 13 & 11 & 17 \\
\hline Administrative duties & 29 & 21 & 15 & 15 & 9.7 & 9 & 27 & 15 & - & - & - & 58 \\
\hline Stabilizing clients & 35 & 65 & - & - & - & - & - & - & 17 & 20 & 48 & 16 \\
\hline $\begin{array}{l}\text { Supporting the clients to manage their } \\
\text { health problems }\end{array}$ & 46 & 60 & - & - & - & - & 37 & 15 & 11 & 9.7 & 0.7 & 20 \\
\hline Supporting the clients during personal crisis & 85 & 54 & - & - & - & - & 13 & 20 & 11 & 9.7 & 18 & 28 \\
\hline $\begin{array}{l}\text { Promoting and supporting a clients social- } \\
\text { network and relationship with family }\end{array}$ & 22 & 15 & 15 & 16 & 22 & 9 & 17 & 18 & 10 & 11 & 10 & 33 \\
\hline $\begin{array}{l}\text { Supporting the clients in recognizing their } \\
\text { potentials and strengths }\end{array}$ & 32 & 40 & 27 & - & - & - & 11 & 12 & 9.7 & 12 & 14 & 41 \\
\hline $\begin{array}{l}\text { Supporting the clients in self-determination } \\
\text { to all decisions concerning their own life }\end{array}$ & 26 & 41 & 33 & - & - & - & 4.4 & 0.7 & 8.5 & 9.1 & 20 & 39 \\
\hline
\end{tabular}

\section{Discussion}

The study reported a high response rate of the registered nurses, indicating a reasonable generalizability of findings, though this is limited by the non-random sample selection. The study included only registered nurses and excluded nurses' assistants who play an important role in delivery of care in mental health hospitals in Greece because registered nurses will play a centered role in community care settings.

The sample was representative for three reasons. These two major psychiatric hospitals are to be closed and nurses' educational background is based on the same nursing schools and the majority of nurses had received a minimum training in mental health nursing.

In order to interpret correctly the findings of this study-except the educational background mentioned above we have to consider that hospitals operate with a major shortage of trained professionals, and nursing profession in the current economic situation in Greece is a low income profession. The fact that personnel shortage has a negative effect on the delivery of care is consistent with previous study [5].
Community mental health nurses' role is extremely important in promoting community care. A study concerning CMHNs' role focused on six main areas which included the day-to-day management of clients, working with carers and their families, crisis work for both existing and first time contacts, as well as liaison and advocacy work. [4]. Previous studies showed that the workload of community mental health nurses is increased by the greater complexity of needs of community mental health clients and the main themes were relating to staffing and workforce issues, clients' characteristics or needs, regional issues, and the impact of the health-care system [6].

\section{Questions concerning our daily work}

In line with World Health Organization's objectives to promote recovery-oriented care [7] research has shown that nurses need support in order to provide assessment and documentation of psychosocial interventions. Nursing interventions in primary care is fundamental to quality of care. Nurses in this study felt inadequate in planning/ documenting care (68.3\%), and in administrating duties (57.9\%) [8]. It has to be noticed that there are no protocols or care plans for nurses to follow in Greek mental hospitals. Concerning documenting of care 
Table 3: Coping with stress and work load $(n=164)$.

\begin{tabular}{|c|c|c|c|c|c|c|}
\hline \multirow{3}{*}{$\begin{array}{l}\text { I experience the following as } \\
\text { especially difficult and/or strenuous }\end{array}$} & \multicolumn{3}{|c|}{ Please put a tick in the scale of $6-1$} & \multicolumn{3}{|c|}{ Difficult/stressful-not difficult/stressful } \\
\hline & 6 & 5 & 4 & 3 & 2 & 1 \\
\hline & $\mathrm{n}(\%)$ & $\mathrm{n}(\%)$ & $\mathrm{n}(\%)$ & $\mathrm{n}(\%)$ & $\mathrm{n}(\%)$ & $\mathrm{n}(\%)$ \\
\hline Working and being alone with clients & $38(23.1)$ & $45(27.4)$ & $63(38.1)$ & $18(10.9)$ & - & - \\
\hline The responsibility for clients in crisis & $64(39.0)$ & $45(27.4)$ & $32(19.5)$ & $23(14.0)$ & - & - \\
\hline "Switching-off" after work & $76(46.3)$ & $53(32.3)$ & $35(21.3)$ & - & - & - \\
\hline Managing aggression & $164(100)$ & - & - & - & - & - \\
\hline Managing self-harm & $164(100)$ & - & - & - & - & - \\
\hline Managing suicidal behaviour / crisis & $164(100)$ & - & - & - & - & - \\
\hline $\begin{array}{l}\text { Managing inappropriate requests } \\
\text { from other disciplines/professionals }\end{array}$ & $22(13.4)$ & $45(27.4)$ & $42(25.6)$ & $38(21.9)$ & 36 (21.9) & - \\
\hline Co-operating with other services & $12(7.3)$ & $35(21.3)$ & $45(27.4)$ & $36(21.9)$ & 36 (21.9) & - \\
\hline $\begin{array}{l}\text { Not having enough time when } \\
\text { working with clients }\end{array}$ & $133(81.1)$ & $31(18.9)$ & - & - & - & - \\
\hline Problems within the team & $58(35.3)$ & $45(27.4)$ & $48(29.2)$ & $13(7.9)$ & - & - \\
\hline Problems with "superiors" & $126(76.8)$ & $25(15.2)$ & $13(7.9)$ & - & - & - \\
\hline
\end{tabular}

nurses has to make decisions based on cognitive continuum theory and exhibit high situation awareness in every clinical case which will lead to a safe clinical care in a community setting [9].

They also considered it very important to build a relationship with the client (96.9\%), communicate with the client (96.9\%), and support the client during personal crisis $(84.8 \%)$, stabilize clients $(64.6 \%)$ and supporting the client to manage their health needs (60.3\%). A study concerning psychiatric nurses' and patients' opinions for suicidal patients has shown that communication with the patients is the most important element in patient care [10]. Additionally nurse-patient relationship may enhance the patient's health and strengthen patient's own resources through recovery [11]. Previous studies have identified the intensification of the workload of CMHNs. Relating to staffing and workforce issues and clients' characteristics and needs is of high priority in the community services [6].

\section{Coping with stress and work load}

Nurses found extremely difficult (6) or very difficult (5) and strenuous almost all aspects of the topics mentioned in this part of the questionnaire; the responsibility for clients in crisis $(39.0 \%)$, "switching-off after work (46.3\%), managing aggression (100\%), managing suicidal behavior (164\%), not having enough time when working with clients $(81.1 \%)$, problems with the team $(35.3 \%)$ and problems with "superiors" (76.8\%). Community Mental health nurses are in danger for high levels of stress and burnout because they combine three major stressful components: high work overload, dealing with mental health problems and in many cases they face a decrease in job satisfaction [12]. A study concerning mental health nurses emotional wellbeing have demonstrated that is linked to professional practice and organizations must address nurses' emotional needs [13].

Nurses play a key role in the management of patients in crisis. Nurses reported their difficulty in managing aggression and suicidal behavior. In a crisis, nurses possibly did not have the time for an appropriate risk assessment. Previous study has shown managing anxiety, aggression and intervening in crisis to be of great importance in everyday practice [14]. Additionally studies have shown that mental health practitioners need a specific training in the implementation of care plans e.g. harm reduction in self harm psychiatric patients in order to feel capable to handle serious situations [15]. Nurses' attitude towards self harm patients is very important and a number of studies have indicated that nurses have a negative attitude which can improve with the help of education [16].

Community work demands high level of preparation for the confrontation of critical incidents given the fact that nurses act usually autonomously. Previous study in Greece has shown that nurses in Greece have inadequate preparation to work in community mental health [17,18]. A study across seventeen European countries has shown that there is a lack of clarity on matters concerning violence management. The theme of prevention seems to be of top priority in nursing training [19]. Additionally nurses' responses revealed the need for specific protocols for the management of aggressive patient. Others countries like Spain developed protocol with exact guidance in order for the patient to be treated in the least coercive manner and nurses to feel safe and capable to deal with it. [20]. Patients' aggression is a major health problem and nurses are often called to manage effectively aggression and its consequences. Previous study found that psychiatric nurses reported low levels of access to learning opportunities and receiving support, lack of clinical guidelines and inadequate autonomy concerning managing aggression which leads to a great dissatisfaction in the workplace [21].

In the community setting nurse have to keep a balance between continuous observation of the patient and taking a risk in decision making. Good decision making require a sufficient collaboration with the patients and the therapeutic team [22]. It is of major importance that nurses referred to "problems with the team" and "working with doctors" as important and strenuous in their everyday practice. Community care is based mainly on continuous care delivered by interdisciplinary teams who functions in patient centered way to 
Table 4: Questions concerning the need for further training $(n=164)$.

\begin{tabular}{|c|c|c|c|c|c|c|}
\hline \multirow{3}{*}{$\begin{array}{l}\text { If you are designing a training program me for } \\
\text { "Community-based Mental Health Care" which } \\
\text { topics would you wish to cover? (please asses the } \\
\text { following topics in a scale from 6-1) }\end{array}$} & \multicolumn{6}{|c|}{$\begin{array}{l}\text { Please put a tick in the scale of } 6-1 \\
\text { Very important-unimportant (\%) }\end{array}$} \\
\hline & 6 & 5 & 4 & 3 & 2 & 1 \\
\hline & n (\%) & n (\%) & n (\%) & $\mathrm{n}(\%)$ & n (\%) & n (\%) \\
\hline $\begin{array}{l}\text { Organizing Healthcare Services (planning and } \\
\text { Documenting care) }\end{array}$ & $25(15.2)$ & $35(21.3)$ & $46(12.8)$ & $23(28.0)$ & $335(21.3)$ & - \\
\hline Assessment (medical, nursing and holistic) & $78(47.5)$ & $65(39.6)$ & $21(12.8)$ & - & - & - \\
\hline $\begin{array}{l}\text { Methodology and Models (therapeutic Approaches, } \\
\text { communication, managing Relationships, counseling) }\end{array}$ & $164(100)$ & - & - & - & - & - \\
\hline $\begin{array}{l}\text { Recovery (adopting a recovery approach In all } \\
\text { aspects of work) }\end{array}$ & - & - & $27(16.4)$ & $36(21.9)$ & $45(27.4)$ & $56(34.1)$ \\
\hline Values (working with values diversity) & - & - & $45(27.4)$ & $58(35.3)$ & $42(25.6)$ & 19 (11.5) \\
\hline $\begin{array}{l}\text { The legal background (NHS and social care policy/ } \\
\text { Legislation, compulsory treatment, legislation } \\
\text { Governing guardianship) }\end{array}$ & $151(92.0)$ & $13(7.9)$ & - & - & - & - \\
\hline Professional role in mental health nursing & $164(100)$ & - & - & - & - & - \\
\hline $\begin{array}{l}\text { Reflective Practice (discussing cases, clinical } \\
\text { supervision, expert advice within the team) }\end{array}$ & $102(62.2)$ & $62(37.8)$ & - & - & - & - \\
\hline Staff Self Awareness and Self-Care & - & - & $13(7.9)$ & $17(10.3)$ & $58(35.3)$ & $76(46.3)$ \\
\hline $\begin{array}{l}\text { Managing crisis (managing aggressions, managing } \\
\text { self-harm and self-injury) }\end{array}$ & $164(100)$ & - & - & - & - & - \\
\hline $\begin{array}{l}\text { Co-operation (with users friends and relatives, With } \\
\text { other vocational groups, with other services) }\end{array}$ & $47(28.6)$ & $52(31.7)$ & $33(20.1)$ & $21(12.8)$ & $11(6.7)$ & - \\
\hline The organizational structure of healthcare systems & - & - & $15(9.1)$ & $25(15.2)$ & $38(23.1)$ & $86(52.4)$ \\
\hline Teamwork with individual colleagues & - & - & - & $35(21.3)$ & $45(27.4)$ & $84(51.2)$ \\
\hline
\end{tabular}

ensure quality of care and the transition between hospital and primary care [23]. Community mental health nurses have more autonomous roles and the relationship with clinicians is a major component of this role [24].

Mental health nurses in the community settings will have to play a consultant/liaison role using the concept of patient-centered nursing care. Concerning the remaining themes in the questionnaire like managing and reflecting distance and proximity, supporting clients in organizing daily life, promoting and supporting a client's socialnetwork and relationship with family and supporting the client in recognizing their potential, strengths, self-determination and decisions concerning their own life we show a diversity in the answers. Diversity in the results is attributed in the different levels of nurses' education in Greece and in the fact that they act without autonomy since the law is not clear concerning nurses' intervention framework. Nurses have inadequate preparation for functioning autonomously and for applying intervention techniques. Nursing continues to be dependent on the medical profession's authority [25].

\section{Training program}

The findings of the present study revealed that nurses are unprepared for community care services. Given the fact that community mental health nurses must be prepared for their future role, a specific defining of what "nurses' role in community settings" means is essential. A study was tried to identify the components of the community based mental health role and found that clinical contact with clients, administrative and care coordination activities were very important [26].

Currently a number of training programs in hospitals address to nurses in order to increase nurses' job satisfaction, communication skills, team relationships and decrease job-stressors and psychological distress $[27,28]$. Additionally a number of education programs for mental health professionals appeared to lead in increased professionals' recovery-promotion behaviors, recovery-oriented practice skills and knowledge [29-31]. Training programs that will integrate evidencebased practice into community nursing practice are also needed [32].

A precise scheduling of a training program based on existing knowledge and usual clinical practice is needed. Previous attempts 
have shown that a training program may have no effect unless the content and the duration are sufficiently examined [33]. Total sample of the Greek Mental Health Nurses mentioned specific deficiencies in their daily work like managing aggression, self-harm and suicidal behavior that need to be considered in a future training program. The management of patient in crisis demands specific guidelines developed by a national center for nursing, nurses' training, the implementation of these clinical guidelines and the assessment of possible results integrating service users views (patient and family) [34].

\section{Limitations}

The non-participation of other health professionals in this study could be a limitation. Nurses reported "problems with the team" and "problems with superior" so future interventions could be more broadly integrated into therapeutic team everyday practice; focused on team's relationships and cooperation. The findings of this research cannot be generalized to nursing as a profession but represent a snapshot of the Greek psychiatric hospitals currently in existence.

\section{Conclusions}

This study assessed the mental health nurse's practices, coping strategies and training needs. Nurses reported high stress and work overload. Nurses have inadequate preparation for functioning autonomously and for applying intervention techniques. Since current nurses will staff future extramural services and will play an important role in patients care, it was deemed important to develop training programs based on these results in order to educate nurses how to implement care policies in evidence based clinical practice. The conclusion is that the existing nursing situation seemed to be unprepared to implement and facilitate community care.

\section{References}

1. Koukia E (2012) Mental health services in Greece. In: Brimblecombe $\mathrm{N}$, Nolan $\mathrm{P}$ (eds) Mental Health Services in Europe. Radcliffe Publishing, London, UK, 121-147.

2. Saraceno B, Gater R, Rahman A, Saeed K, Eaton J, et al. (2015) Reorganization of mental health services: from institutional to community-based models of care. East Mediterr Health J 21: 477 485.

3. Jie Li, Juan Li, Graham Thornicroft, Hui Yang, Wen Chen, et al. (2015) Training community mental health staff in Guangzhou, China: evaluation of the effect of a new training model. BMC Psychiatry 15: 263.

4. Zeeman Z, Chapman R, Wynaden D, McGowan S, Lewis M, et al. (2002) Community mental health care: documenting the role of the nurse. Contemp Nurse 12: 112-123.

5. Saxena S, Thornicroft G, Knapp M, Whiteford H (2007) Resources for mental health: scarcity, inequity, and inefficiency. Lancet 370 : 878-889.

6. Henderson J, Willis E, Walter B, Toffoli L (2008). Community mental health nursing: keeping pace with care delivery? Int J Ment Health Nurs 17: 162-170.

7. WHO (2013). Mental health action plan 2013-2020, Geneve.

8. Cusack E, Killoury F, Nugent LE (2017) The professional psychiatric/ mental health nurse: skills, competencies and supports required to adopt recovery-orientated policy in practice. J Psychiatr Ment Health Nurs 24: 93-104.

9. Tower M, Chaboyer W, Green Q, Dyer K, Wallis M (2012). Registered nurses' decision-making regarding documentation in patients' progress notes. J Clin Nurs 21: 2917-2929.
10. McLaughlin C (1999) An exploration of psychiatric nurses' and patients' opinions regarding in-patient care for suicidal patients. J Adv Nurs 29: 1042-1051.

11. Strandås $M$, Bondas $T$ (2018) The nurse-patient relationship as a story of health enhancement in community care: A metaethnography. J Adv Nurs 74: 11-22.

12. Fiabane E, Giorgi I, Squazzin C, Argentero P (2013) Work engagement and occupational stress in nurses and other healthcare workers: the role of organisational and personal factors. J Clin Nurs 22: 26142624.

13. Rose J, Glass N (2006) Community mental health nurses speak out: the critical relationship between emotional wellbeing and satisfying professional practice. Collegian 13: 27-32.

14. Haddad M, Plummer S, Taverner A, Gray R, Lee S, et al. (2005) District nurses' involvement and attitudes to mental health problems: a three-area cross-sectional study. J Clin Nurs 14: 976-985.

15. James K, Samuels I, Moran P, Stewart D (2017) Harm reduction as a strategy for supporting people who self-harm on mental health wards: the views and experiences of practitioners. J Affect Disord 214: 67-73.

16. Karman P, Kool N, Poslawsky IE, van Meijel B (2014) Nurses' attitudes towards self-harm: a literature review. J Psychiatr Ment Health Nurs 22: 65-75.

17. Koukia E, Madianos MG, Katostaras T (2009) "On the spot" interventions by mental health nurses in inpatient psychiatric wards in Greece. Issues Ment Health Nurs 30: 327-336.

18. Koukia E, Zyga S (2013) Critical cases faced by Mental Health Nurses and Assistant nurses in Psychiatric Hospitals in Greece. Int J Caring Sci 6: 465-471.

19. Cowman S, Björkdahl A, Clarke E, Gethin G, Magouire J (2017) A descriptive survey study of violence management and priorities among psychiatric staff in mental health services, across seventeen european countries. BMC Health Serv Res 17: 59.

20. Vieta $E$, Garriga $M$, Cardete $L$, Bernardo $M$, Lombraña $M$, et al. (2017) Protocol for the management of psychiatric patients with psychomotor agitation. BMC Psychiatry 17: 328.

21. Ramezani T, Gholamzadeh S, Torabizadeh C, Sharif F, Ahmadzadeh L (2017) Challenges of Nurses' Empowerment in the Management of Patient Aggression: A Qualitative Study. Iran J Nurs Midwifery Res 22: 442-448.

22. Barnicot $K$, Insua-Summerhayes B, Plummer E, Hart A, Barker $C$, et al. (2017) Staff and patient experiences of decision-making about continuous observation in psychiatric hospitals. Soc Psychiatry Psychiatr Epidemiol 52: 473-483.

23. Peterson K, Helfand M, Humphrey L, Christensen V, Carson S (2013) VA Evidence-based Synthesis Program Evidence Briefs [Internet]. Washington (DC): Department of Veterans Affairs (US); 2011-VA Evidence-based Synthesis Program Reports.

24. Elsom S, Happell B, Manias E (2007) Expanded practice roles for community mental health nurses: what do consumers and carers have to say? Issues Ment Health Nurs 28: 1065-1079.

25. Soltis-Jarrett $\vee$ (2016) Patient-Centered Homes and Integrated Behavioral Health Care: Reclaiming the Role of "Consultant" for Psychiatric-Mental Health Nurse Practitioner. Issues Ment Health Nurs 37: 387-391.

26. Heslop B, Wynaden D, Tohotoa J, Heslop K (2016) Mental health nurses' contribution to community mental health care: An Australian study. Int J Ment health Nurs 25: 426-433. 
27. Nakamura Y, Yoshinaga N, Tanoue H, Kato S, Nakamura S, et al. (2017) Development and evaluation of a modified brief assertiveness training for nurses in the workplace: a single-group feasibility study. BMC Nurs 16: 29.

28. Usher K, Park T, Trueman S, Redman-Maclaren M, Casella E, et al. (2014) An educational program for mental health nurses and community health workers from pacific island countries: results from a pilot study. Issues Ment Health Nurs 35: 337-343.

29. Gale J, Marshall-Lucette S (2012) Community mental health nurses' perspectives of recovery-oriented practice. J Psychiatr Ment Helath Nurs 19: 348-353.

30. Higgins A, Callaghan P, DeVries J, Keogh B, Morrissey J, et al. (2012) Evaluation of mental health recovery and Wellness Recovery Action Planning education in Ireland: a mixed methods pre-postevaluation. J Adv Nurs 68: 2418-2428.

31. Slade M, Bird V, Clarke E, Le Boutillier C, McCrone P, et al. (2015) Supporting recovery in patients with psychosis through care by community-based adult mental health teams (REFOCUS): a multisite, cluster, randomised, controlled trial. Lancet Psychiatry 2: 503-514.

32. Duncombe DC. (2017) A multi-institutional study of the perceived barriers and facilitators to implementing evidence-based practice. J Clin Nurs 27: 1216-1226.

33. Zuaboni G, Hahn S, Wolfensberger P, Schwarze T, Richter D (2017) Impact of a Mental Health Nursing Training-Programme on the Perceived Recovery-Orientation of Patients and Nurses on Acute Psychiatric Wards: Results of a Pilot Study. Issues Ment Health Nurs 38: 907-914.

34. National Collaborating Centre for Mental Health (UK) (2015) Violence and Aggression: Short-Term Management in Mental Health, Health and Community Settings: Updated edition. London: British Psychological Society, National Institute for Health and Care Excellence: Clinical Guidelines. 